\title{
Quantitative Assessment of Construction and Demolition Waste
}

\author{
S.Vinothkumar, C.Anish, S.Venkatraman, S.Rajesh
}

\begin{abstract}
Construction Industry is in the great danger and in a major crisis creating greater impact to the environment. The analysis is carried out in order to find the sources that generates the construction waste at the initial stage and the contribution rates of those waste. This thesis also deals with the waste reduction procedures. Showing the results to the future consideration enabling to the quote "Construction waste management to the future generation
\end{abstract}

\section{Keywords - Waste Management, Construction Waste.}

\section{INTRODUCTION}

Construction waste arises from various stages of construction contributing and influencing the construction industry. Construction waste is often found in the unused areas and becoming as a debry. These wastes are to be reduced which can be eliminated and reduced from the initial stage of construction. For this, the resources are to be analysed and their contribution to the waste are classified. [1]-[5]Construction waste arises mostly due to improper management techniques and material handling. The construction waste can also arise due to the following sources such as procurement, workers mistakes, material handling, management plan, site conditions, logistics, operations, misplacement, manufacturing and other external sources such as harsh weather conditions The major components of construction waste as per Indian conditions are cement, concrete, bricks, cement plaster, steel from RCC door, window frames, roofing supports and railing of staircase, wood, timber, rubble and stones such as marble, granite and sandstone. The minor components such as pipes such as Galvanised Iron pipes and plastic pipes, electrical fixtures such as copper and aluminium wiring, panels and glazed tiles.

The analysis of the project is based on the two factors frequency and severity. The data is collected with respect to how frequent the waste is contributed and how severe the impacts can contribute. Frequency is the measure of how often the sources contribute to construction waste. Severity is the measure of the extent of the impact of these sources in terms of volume of waste that can be generated[6]-[8]. These two parameters play a vital role in determining the results of

Revised Manuscript Received on October 22, 2019.

S.Vinothkumar, Department of Civil Engineering, Bharath Institute of Higher Education and Research, Chennai , India. Email: vinothsenna@gmail.com

C.Anish, Department of Civil Engineering, Bharath Institute of Higher Education and Research, Chennai , India. Email: anishdavidpaul@gmail.com

S.Venkatraman , Department of Civil Engineering, Bharath Institute of Higher Education and Research, Chennai , India. Email: mailmagik@yahoo.com

S. Rajesh , Department of Civil Engineering, Bharath Institute of Higher Education and Research, Chennai , India. Email: rajeshskr06@gmail.com the study. The data collected is quantified with respect to these parameters. In order to prove the percentage of contribution, these parameters become necessary.

The objective is to develop mitigation strategy and mitigation measures to reduce the percentage of waste from the quantitative analysis of sources of construction waste and its causative factors

The scope of the project is

- To determine the input based on frequency and severity by data collection

- To develop analysis based on sources identified

- To incorporate mitigation strategy based on causative factors

- To find mitigation measures to reduce the contribution of waste

\section{A. Need for the Study}

Construction waste is increasing day by day. This study is carried out in order to find the sources at the initial stage and reduce them from the source factor itself. The development of such model is to create a great impact on reducing the site waste caused during construction[9]-[10].

This study also focuses on improving managerial commitment towards waste management.

\section{B. Sources of Construction Waste}

The contributors of construction waste are usually the owners, contractors, logistics, site management, manufacturer, procurement, supplier and designer. The generators of construction waste are classified into two such as bulk generators and small generators. The bulk generator comprises of waste from roads, bridges, flyover, flats, parks and malls. The small generator comprises of waste from houses and small buildings. Construction and demolition waste is divided into three categories which includes material, labor and machinery.

The waste behavior in theconstruction industry and recommended to help managers improve attitude towards construction waste. This study focused on improving managerial commitment towards waste management. The observations revealed that operatives see waste as an inevitable by-product of construction industry. Waste management is perceived as a low project priority, and there is an absence of appropriate resources and incentives to support it. 
The methodology of 5R concept such as refuse, reuse, reduce, recycle and reinvent was adopted. It also highlighted the problems faced by the construction industry. The survey conducted suggests that most of the waste goes to the landfill. The study revealed that the variation in the design/drawing and last minute changes in project scope are the most important causes of generation of waste.

The source of construction waste has been identified and many strategies to reduce the waste from these sources were found from the study[11]-[15].

It was also observed that quantitative terms were used to reduce such waste. The observation from literatures suggested that survey was done through manual survey in most of the countries. In most cases sources of construction waste and its causes has been identified. The mitigation strategies were given only through theories.

\section{RESEARCH METHODOLOGY}

The methodology adopted for research is quantitative research method. Information about the world is acquired through this method. It is typically sample survey and experiment. The quantitative research method is used to describe variables, examine relationships among variables and explore the strength of each variable. The research methodology is divided into two segments[16]-[18].

\section{Data collection through questionnaire survey}

\section{Quantitative Analysis}

Questionnaire survey consists of two sections. The first section had the details of the respondent and organization details. The second section had the frequency and severity of contribution rates of waste sources and its causative factors. Data collection is done based on the various sources of construction waste and its causative factors. For the corresponding source, various causative factors were determined.

The sources of waste were classified into eleven groups such as procurement, design, workers mistakes, management plan, material handling, site condition, logistics, manufacturing, operations, misplacement and external sources. Based on the source and causative factors, manual survey and online survey were done. The questionnaire survey was in the form of 5 point likert scale determining the contribution rates of each causative factor. The contribution rates were segregated into frequency contribution rates and severity contribution rates. The 5 point likert scale mentioned 1 to be no contribution, 2 as little contribution, 3 as moderate contribution, 4 as high contribution and 5 as extreme contribution[19]-[20].

The second phase of the methodology is the analysis phase. The analysis has been done using Minitab17. This phase is classified into five stages. In the initial stage the response from the respondents are entered in Minitab17 software. involves finding ordinal logistic regression.
The second stage of analysis involves finding goodness of fit, which is based on pearson and deviance value. The third stage of analysis is finding correlation matrix. The fourth stage of analysis is finding cronbach value for testing its reliability. The fifth stage of analysis is finding the contribution rates using the formulae. The contribution rates are found only if data is reliable.

- Identifying the sources of waste is the primary step to find the generation points and carry out further computations.

- Recognizing its causes is the key to find reasons for the generation of waste.

\section{A. Data Collection}

Data collection is the primary step for doing analysis or quantifying a term. Data collection is the procedure of collecting and measuring statistics on centered variables in a longtime systematic fashion, which then allows one to reply applicable questions and evaluate consequences. The information collection thing of studies is not unusual to all fields of look at which includes bodily and socialsciences, humanities and enterprise. It helps scientists and analysts to gather the mainpoints as amassed records. While strategies vary with the aid of area, the emphasis on making sure correct and sincere series remains the identical. The purpose for all records collection is to seize first-rate evidence that then translates to rich information evaluation and permits the constructing of a convincing and credible answer to questions that have been posed. Regardless of the field of study or preference for defining data (quantitative or qualitative), accurate data collection is essential to maintaining the integrity of research. Both the selection of appropriate data collection instruments (existing, modified, or newly developed) and clearly delineated instructions for their correct use reduce the likelihood of errors occurring. The data collection was done by two methods. The first method was data collection through manual survey[21]-[24]. The second method was data collection through online survey. The data collected encountered 72 respondents from which 32responses were collected manually and 40 were collected through online survey. The data was collected in appropriate method in order to match its reliability. The data was collected in the form of likert scales. The data was collected with respect to frequency and severity on contribution rates of sources of construction waste.

- Data Collection

- Quantitative Analysis Of The Data Collected

- Ordinal Logistic Regression

- Goodness Of Fit

- Correlation Matrix

- Reliability Test

- Contribution Rate

- Mitigation Strategy

\section{B. Quantitative Analysis Of The Data Collected}


The data collected from the respondents were converted to quantitative form using Microsoft Excel and Minitab 17 software.

The numerical data was collected and entered in Minitab 17 software for further carrying out various analyses. Quantitative analysis includes finding reliability of the data and computing contribution rated to find reduction in percentage of waste. To find reliability of the data Minitab17 is used and to find the contribution rates formulae are developed and computed with help of Microsoft Excel[25]-[27].

\section{Ordinal Logistic Regression}

In measurements, ordinal relapse (likewise called "ordinal arrangement") is a kind of relapse examination utilized for foreseeing an ordinal variable, for example a variable whose worth exists on a discretionary scale where just the relative requesting between various esteems is huge. It very well may be viewed as a halfway issue among relapse and grouping. Instances of ordinal relapse are requested logit and requested probit. Ordinal relapse turns up frequently in the sociologies, for instance in the demonstrating of human levels of inclination (on a scale from, state, 1-5 for "poor" through "fantastic"), just as in data recovery. In AI, ordinal relapse may likewise be called positioning learning. The relapse investigation is the relapse model for customary ward esteems. In relapse investigation, the accompanying points, for example, coefficient of assurance (The R-squared proportion of integrity of fit), Lack of fit aggregate of squares, diminished chi-square identify with decency of fit.

The regression analysis helps in finding the p-values which should be less than or equal to 0.05 for $95 \%$ significance level. The p-values should be less than or equal to 0.01 for $99 \%$ significance level. In this study $95 \%$ significance level is adopted. The analysis was done between each identified source of construction waste. The analysis was performed using Minitab17 software[28].

\section{Goodness Of Fit}

The extent to which observed data matches the values expected by theory. The integrity of attack of a measurable model portrays how well it fits a lot of perceptions. Proportions of integrity of fit ordinarily condense the error between watched esteems and the qualities expected under the model being referred to. Such measures can be utilized in factual theory testing, for example to test for ordinariness of residuals, to test whether two examples are drawn from indistinguishable conveyances (see Kolmogorov-Smirnov test), or whether result frequencies pursue a predetermined dispersion (see Pearson's chi-squared test). In the examination of change, one of the segments into which the fluctuation is parceled might be an absence of-fit entirety of squares.

\section{E. Correlation Matrix}

Correlation is any of an expansive class of factual connections including reliance, however in like manner use it regularly alludes to the degree to which two factors have a direct association with one another. Commonplace instances of ward marvels incorporate the connection between's the physical statures of guardians and their posterity, and the relationship between's the interest at an item and its cost.

The relationship framework worth ought to be 0 to 1 . The connection lattice characterizes the quality and connection between two factors. The higher the qualities the more prominent the factors are corresponded.

\section{F. Reliability Test}

A measure is said to have a high reliability if it produces similar results under consistent conditions. "It is the characteristic of a set of test scores that relates to the amount of random error from the measurement process that might be embedded in the scores. Scores that are highly reliable are accurate, reproducible, and consistent from one testing occasion to another. That is, if the testing process were repeated with a group of test takers, essentially the same results would be obtained. Various kinds of reliability coefficients, with values ranging between 0.00 (much error) and 1.00 (no error), are usually used to indicate the amount of error in the scores."

\section{G. Mitigation Strategy}

The reliability test is the approach to check whether the data collected is reliable or not. The reliability of the data depends on the cronbach's value. This value should be greater than 0.7 and less than 1 . If the variables fall below the limits, that particular variable is omitted and analysis is continued. The values closer to 1

\section{RESULT AND DISCUSSION}

The information obtained from small scale construction industries proved that they have poor knowledge about the aftermath of the waste generated. The percentage of recycling in construction industry is low. Construction wastes that are often reused are concrete, wood and bricks. In Indian scenario it becomes important to impart waste management tool for residential, industrial, commercial and infrastructure projects[29]-[30]. The purpose of such tool is to estimate the quantity of waste that can be generated in the ongoing projects. The study from various construction industries proved that the importance given to waste management tool in India is very low.

The results obtained from ordinal logistic regression, goodness of fit, correlation matrix paved way to find reliability of the data. The positive results from reliability test helped to find the contribution rates for the sources of construction waste. Considering procurement and design as the source the ordinal logistic regression value for frequency is 0.000 which is less than 0.05 . The value remains the same for ordinal logistic regression for severity. This source is now qualified to find the goodness of fit. The value for goodness of fit is based on pearson and deviance value.

The pearson and deviance value for frequency is 0.321 and 0.415 respectively. The 
pearson and deviance value for severity is 0.769 and 0.935 . These sources are now eligible to find the correlation matrix. The correlation matrix values should lie in the range 0 to 1 .

The correlation matrix values of procurement and design for frequency and severity are 0.666 and 0.683 respectively. The positive results helped in finding the reliability of the data which is based on cronbach's value. This cronbach's value should lie in the 0.7 to 1 . The cronbach value for procurement and design in frequency proves to be 0.9334 and 0.9272 . The value for severity proves to be 0.9285 and 0.9265 . The data obtained based on sources are reliable and contribution rates of the source are found.

The best fit in the analysis is management plan and manufacturing. The goodness of fit value based on frequency is 0.999 and 0.994 . The goodness of fit value based on severity is 1 and 0.998 . The theory proves that the higher the goodness of fit value the higher the contribution rate.

The results of the reliability test is found and computed for further analysis. The reliability test analysis is computed based on cronbach value. Cronbach value is computed for both frequency and severity. The cronbach value of procurement for frequency is 0.9334 . The cronbach value of design for frequency is 0.9272 . The cronbach value of workers mistakes for frequency is 0.9285 . The cronbach value of Management Plan for frequency is 0.9237 . The cronbach value of Material handling for frequency is 0.9249 . The cronbach value of site condition for frequency is 0.9279 . The cronbach value of logistics for frequency is 0.9232 . The cronbach value of manufacturing for frequency is 0.9256 . The cronbach value of operations for frequency is 0.9286 . The cronbach value of misplacement for frequency is 0.9358 . The cronbach value of external sources for frequency is 0.9302 .

The analysis from the study projected the waste percentage of $11.289 \%$ which has been found for management plan. This means that proper management plans will have to be adopted such as adequate planning, controlling and supervision[31]-[32]. Appropriate construction methods have to be followed. Waste Management Plans must be installed and monitored regularly. Adopting such strategies reduces the waste percentage for management by $6.66 \%$. For workers mistakes, waste contributed is computed to be $10.686 \%$. To minimize these waste, the training for workers should be sufficient, the worker must be monitored frequently to minimize damages. The waste caused due to workers mistakes can be reduced by $5.64 \%$.

The waste due to design contributes about $10.324 \%$. The waste can be mitigated by adopting proper design, improving design information and avoiding inexperienced designer. The mitigation strategies for design can be reduced by $5.67 \%$. The waste from manufacturing contributes about $9.867 \%$. To reduce such waste it is important to manufacture the material with standard sizes, good quality and adequate product information. Manufacturing waste can be reduced by $5.85 \%$ if the mitigation strategies are followed[33]-[36].

The waste from poor site conditions contributed $9.394 \%$. The waste generated from site conditions can be minimized by improving lighting facilities, avoiding congestion of materials. These strategies reduce the waste by about $5.41 \%$.
The waste generation from material handling contributes $9.25 \%$ of total waste contributed. To diminish such waste, the material should be stored in a suitable place, damage during transporting must be reduced and the tools which are not suitable should be avoided. Material handling waste can be reduced by $5.30 \%$.

Procurement errors contributed $9.062 \%$ of total waste. To minimize the waste contributed, ordering errors, errors in shipping, mistakes in quantity surveying should be avoided. Adopting the strategies the waste reduces by $5.11 \%$. Improper logistics contributed $8.719 \%$. These wastes are reduced by following appropriate delivery method and appropriate delivery schedule. The mitigation strategies for logistics can reduce the waste by $4.72 \%$.

The waste from operation error contributed $7.673 \%$. The strategy adopted to reduce such waste is by reducing error caused due to worker specialised in a particular work. Operation waste can be reduced by about $4.43 \%$. The external sources contribute about $7.026 \%$ of waste. The waste can be reduced by restricting workers from theft, adopting safety measures to prevent accidents and taking precautionary measures during natural disasters. Adopting the mitigation strategies for external sources reduces the waste by $4.21 \%$.

Based on the contribution rates of different sources of construction waste, the mitigation strategy is adopted and applied to minimize the waste to maximum extent.

\section{CONCLUSION}

The sources of construction waste and its causative factors were identified. Based on the responses from respondents the identified sources were analysed and tested to check its reliability. The positive results from the analysis helped in carrying forward the data to find the contribution rates of sources of waste and its causative factors.

\section{REFERENCES}

1. Iyappan L., Dayakar P., Identification of landslide prone zone for coonoortalukusing spatial technology, International Journal of Applied Engineering Research,V-9,I-22,PP-5724-5732,Y-2014.

2. Kumar J., Sathish Kumar K., Dayakar P.,Effect of microsilica on high strength concrete, International Journal of Applied Engineering Research,V-9,I-22,PP-5427-5432,Y-2014.

3. Dayakar P., Vijay Ruthrapathi G., Prakesh J., Management of bio-medical waste, International Journal of Applied Engineering Research,V-9,I-22,PP-5518-5526,Y-2014.

4. Swaminathan N., Dayakar P., Resource optimization in construction project, International Journal of Applied Engineering Research,V-9,I-22,PP-5546-5551,Y-2014.

5. Venkat Raman K., Dayakar P., Raju K.V.B.,An experimental study on effect of cone diameters in penetration test on sandy soil, International Journal of Civil Engineering and Technology,V-8,I-8,PP-1581-1588,Y-2017.

6. Saritha B., Chockalingam M.P.,Photodradation of malachite green DYE using TIO2/activated carbon composite,International Journal of Civil Engineering and Technology,V-8,I-8,PP-156-163,Y-2017

7. Shendge R.B., Chockalingam M.P., Saritha B., Ambica A.,Swat modelling for

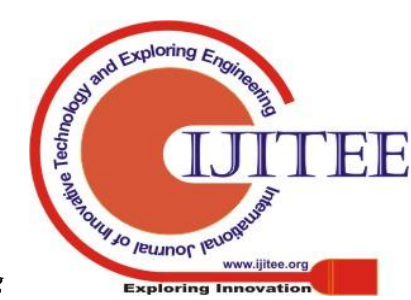


sediment yield: A case study of Ujjani reservoir in Maharashtra, India,International Journal of Civil Engineering and Technology,V-9,I-1,PP-245-252,Y-2018

8. Chockalingam M.P., Balamurgan V.,Modernisation of an existing urban road-sector in Chennai, a case study report,International Journal of Civil Engineering and Technology,V-8,I-8,PP-1457-1467,Y-2017

9. Saritha B., Chockalingam M.P.,Adsorption study on removal of basic dye by modified coconut shell adsorbent, International Journal of Civil Engineering and Technology,V-8,I-8,PP-1370-1374,Y-2017

10. Saritha B., Chockalingam M.P.,Adsorptive removal of heavy metal chromium from aqueous medium using modified natural adsorbent,International Journal of Civil Engineering and Technology,V-8,I-8,PP-1382-1387,Y-2017

11. Chockalingam M.P., Palanivelraja S.,Retrospective analysis of a theoretical model used for forecasting future air quality near the north Chennai thermal power plant,International Journal of Civil Engineering and Technology,V-8,I-8,PP-1457-1467,Y-2017

12. Saritha B., Chockalingam M.P.,Photodegradation of methylene blue dye in aqueous medium by $\mathrm{Fe}-\mathrm{AC} / \mathrm{TiO} 2$ Composite,Nature Environment and

Pollution

Technology,V-17,I-4,PP-1259-1265,Y-2018

13. Shendge R.B., Chockalingam M.P., Kaviya B., Ambica A.,Estimates of potential evapotranspiration rates by three methods in upper Bhima Basin, In Maharashtra, India,International Journal of Civil Engineering and Technology,V-9,I-2,PP-475-480,Y-2018

14. Shendge R.B., Chockalingam M.P.,The soil and water assessment tool for Ujjani Reservoir,International Journal of Mechanical Engineering and Technology,V-9,I-2,PP-354-359,Y-2018

15. Shendge R.B., Chockalingam M.P.,A review on soil and water assessment tool,International Journal of Mechanical Engineering and Technology,V-9,I-2,PP-347-353,Y-2018

16. Sachithanandam P., Meikandaan T.P., Srividya T.,Steel framed multi storey residential building analysis and design,International Journal of Applied Engineering Research,V-9,I-22,PP-5527-5529,Y-2014

17. Meikandaan T.P., Ramachandra Murthy A.,Study of damaged RC beams repaired by bonding of CFRP laminates,International Journal of Civil Engineering and Technology,V-8,I-2,PP-470-486,Y-2017

18. Meikandaan T.P., Ramachandra Murthy A.,Retrofittng of reinforced concrete beams using GFRP overlays,International Journal of Civil Engineering and Technology,V-8,I-2,PP-423-439,Y-2017

19. Meikandaan T.P., Ramachandra Murthy A.,Flexural behaviour of RC beam wrapped with GFRP sheets,International Journal of Civil Engineering and Technology,V-8,I-2,PP-452-469,Y-2017

20. Meikandaan T.P., Murthy A.R.,Experimental study on strengthening of rc beams using glass Fiber,International Journal of Civil Engineering and Technology,V-9,I-11,PP-959-965,Y-2018

21. Meikandaan T.P., Hemapriya M.,Use of glass FRP sheets as external flexural reinforcement in RCC Beam,International Journal of Civil Engineering and Technology,V-8,I-8,PP-1485-1501,Y-2017

22. Saraswathy R., Saritha B.,Planning of integrated satellite township at Thirumazhisai,International Journal of Applied Engineering Research,V-9,I-22,PP-5558-5560,Y-2014

23. Saritha B., Ilayaraja K., Eqyaabal Z.,Geo textiles and geo synthetics for soil reinforcement,International Journal of Applied Engineering Research,V-9,I-22,PP-5533-5536,Y-2014

24. Ambica A., Saritha B., Changring G., Singh N B., Rajen M., Salman Md.,Analysis of groundwater quality in and around Tambaram taluk, Kancheepuram district,International Journal of Civil Engineering and Technology,V-8,I-8,PP-1362-1369,Y-2017

25. Arunya A., Sarayu K., Ramachandra Murthy A., Iyer N.R.,Enhancement of durability properties of bioconcrete incorporated with nano silica,International Journal of Civil Engineering and Technology,V-8,I-8,PP-1388-1394,Y-2017

26. Ilayaraja K., Krishnamurthy R.R., Jayaprakash M., Velmurugan P.M., Muthuraj S.,Characterization of the 26 December 2004 tsunami deposits in Andaman Islands (Bay of Bengal, India),Environmental Earth Sciences,V-66,I-8,PP-2459-2476,Y-2012

27. Ilayaraja K.,Morphometric parameters of micro watershed in Paravanar sub-basin, Cuddalore District,International Journal of Civil Engineering and Technology,V-8,I-8,PP-1444-1449,Y-2017

28. Ilayaraja K., Singh R.K., Rana N., Chauhan R., Sutradhar N.,Site suitability assessment for residential areas in south Chennai region using remote sensing and GIS techniques, International Journal of Civil Engineering and Technology,V-8,I-8,PP-1468-1475,Y-2017

29. Ilayaraja K., Reza W., Kumar V., Paul S., Chowdhary R.,Estimation of land surface temperature of Chennai metropolitan area using
Landsat images,International Journal of Civil Engineering and Technology,V-8,I-8,PP-1450-1456,Y-2017

30. Chitra R.,Experimental study on beam using steel fiber and latex,International Journal of Civil Engineering and Technology,V-8,I-8,PP-1395-1403,Y-2017

31. Chitra R.,Analysis of traffic and management at Kovilambakkam intersection,International Journal of Civil Engineering and Technology,V-8,I-8,PP-1433-1443,Y-2017

32. Aswathy M.,Experimental study on light weight foamed concrete,International Journal of Civil Engineering and Technology,V-8,I-8,PP-1404-1412,Y-2017

33. Aswathy M.,Wastewater treatment using constructed wetland with water lettuce (Eichornia Crasipies),International Journal of Civil Engineering and Technology,V-8,I-8,PP-1413-1421,Y-2017

34. Kiruthiga K., Anandh K.S., Gunasekaran K, Assessment of influencing factors on improving effectiveness and productivity of construction engineers, 2015, International Journal of Applied Engineering Research, V - 10,I -17,p -13849-13854.

35. 35. Srinivasan, G.R. \& Palani, S. 2018, "Physicochemical analysis and economic evaluation of lake ecosystem - A case study of lake system in Walajah Taluk, Vellore (India)", Water and Energy International, vol. 61RNI, no. 3, pp. 52-55.

36. 36. Srinivasan GR, Palani S, Manohanam A, Jambulingam R Assessment of Groundwater Quality of Water Samples Collected From Vellore Co-Operative Sugar Mill, Vellore. Asian Man (The)-An International Journal. 2018;12(2):216-8.

\section{AUTHORS PROFILE}

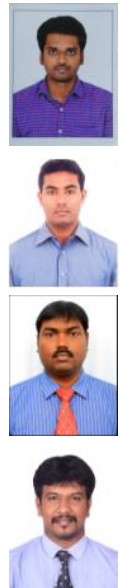

S.Vinothkumar Assistant Professor, Department of Civil Engineering, Bharath Institute of Higher Education and Research, Chennai, India.

C. Anish Assistant Professor, Department of Civil Engineering, Bharath Institute of Higher Education and Research, Chennai , India.

S. Venkatraman Assistant Professor, Department of Civil Engineering, Bharath Institute of Higher Education and Research, Chennai, India

S. Rajesh Assistant Professor, Department of Civi Engineering, Bharath Institute of Higher Education and Research, Chennai, India 